\title{
Regulation of cartilage and inflammatory biomarkers in rheumatoid arthritis patients treated with green tea therapy
}

\author{
Sami A. Gabr ${ }^{1,2}$, Ahmad H. Alghadir ${ }^{2}$ and Gehan A. Ghoniem ${ }^{3}$ \\ ${ }^{1}$ Electron Microscope Unit, Department of Anatomy, Faculty of Medicine, Mansoura University, Mansoura, Egypt. \\ ${ }^{2}$ Department of Rehabilitation Science, College of Applied Medical Sciences, King Saud University, Riyadh, KSA. \\ ${ }^{3}$ Food Industries Department, Faculty of Agriculture, Mansoura University, Mansoura, Egypt.
}

Received 12 May, 2013; Accepted 18 February, 2014

\begin{abstract}
Most of the conventional rheumatoid arthritis (RA) drugs used have severe adverse reactions. Therefore, natural plant products are continuously being sought for the management of RA. In the present study, in vitro antioxidant, joint protective and anti-inflammatory activity of aqueous green tea extract (AGTE) was evaluated in 50 patients with early RA, 30 patients with established RA and 50 healthy control subjects. All patients received 4 to 6 cups/day; 60 to $125 \mathrm{mg}$ catechins of green tea for 24 weeks. The results obtained indicated that green tea possesses potent joint protective and antiinflammatory action against RA by lowering disease activity parameters and improving COMP, HA, IL-6, and TNF-œ. The biochemical observations were supplemented with radiographic analysis of RA patients. In vitro 1,1-diphenyl-2-picryldrazil (DPPH) radical scavenging and NBT assay tests of the green tea exhibited a moderate antioxidant activity $(90.3$ and $87.9 \%)$ in both tests used. The possible mechanism(s) of green tea extract (AGTE) activity may be due to free radical scavenging potential caused by the presence of antioxidant component(s) in AGTE. Consequently, green tea can be used as a therapeutic regime in treatment of some RA disorders.
\end{abstract}

Key words: Cartilage oligomeric matrix protein (COMP), interluken-6 (IL-6), tumor necrosis factor (TNF-œ), rheumatoid arthritis, green tea, disease activity score (DAS)-28, pain numerical rating score (PNRS), European League Against Rheumatism Response (EULAR) criteria.

\section{INTRODUCTION}

Rheumatoid arthritis (RA) is most prevalent in individuals aged 40 years or older with the risk of being up to 5 times higher in women (Brosseau et al., 2004). RA is the most common form of chronic joint inflammation which leads to varying degrees of functional impairment and disability. It is characterized by chronic low-grade inflammation of multiple joints with periodic flare-ups of great intensity that lead to severe and irreversible cartilage, bone and joint destruction (Smith and Haynes, 2002; Lipsky, 2005).

The severity of RA ranges from self-limited swelling in a

*Corresponding author. E-mail: nadalab2009@hotmail.com, Dr.Gabr@hotmail.com, sgabr@ksu.edu.sa. Tel: +966562060018; +96614698543. Fax: +96614698541

Author(s) agree that this article remain permanently open access under the terms of the Creative Commons Attribution License 4.0 International License 
limited number of joints to chronic progressive destruction of multiple joints with reduced muscle strength and impaired physical function (Ekdahl and Broman, 1992). The cytokine network in RA is a complex and dynamic system in which cellular and humoral cytokines, chemokines, and growth factors regulate the initiation and perpetuation of inflammation (Choy and Panayi, 2001).

Previously, it has been shown that serum cytokine levels when screened are useful biomarkers for the diagnosis and prognosis of early inflammatory arthritis (Firestein, 2004; Hitchon et al., 2004), a dramatic increase in the proinflammatory cytokines such as tumour necrosis factor alpha (TNF- $\alpha$ ), interleukin-6 (IL-6), interleukin-1 $\beta$ (IL-1 $\beta$ ), and C-reactive protein (CRP) was reported in patients with RA (Mclnnes, 2003; Sattar et al., 2003).

Early confirmation of RA is important because aggressive therapy during the earliest stages of disease can lead to decreased disease activity and reduced joint damage (Kroot et al., 2002). Molecular-marker technology reported that cartilage oligomeric matrix protein (COMP) and hyaluronic acid may aid as promising candidates in evaluating the disease activity in early RA using immunoassay techniques (ELISAs) (Saxne and Månsson, 2000; Den Broeder et al., 2002; Majeed et al., 2004). It was reported that serum levels of COMP significantly correlates with low values of traditional prognostic markers including erythrocyte sedimentation rate (ESR), C-reactive protein (CRP), rheumatoid factor (Rf) and disease activity score (DAS) (Skoumal et al., 2003).

Non-steroidal anti-inflammatory drugs have formed the mainstay of treatment of RA, but their prolonged use is associated with adverse reactions and discomfort (Kremers et al., 2004). Therefore, natural plant products that are beneficial against arthritis are continuously being sought for the management of RA (Berman, 2004). However, the mechanisms of action of such products are largely unexplored.

Multiple studies were conducted on the effect of green tea (GTPs) in arthritis using in vitro and in vivo animal models (Ahmed et al., 2002; Singh et al., 2002). These studies suggest that GTPs given in drinking water of mice prevented collagen-induced arthritis in the mice, and that this effect of GTPs was associated with the marked reduction of collagen-induced inflammatory mediators such as cyclooxygenase-2 and TNF- $\alpha$ in arthritic joints of GTP-fed mice (Haqqi et al., 1999). The polyphenolic compounds isolated from green tea extracts are rich in antioxidants that possess anti-inflammatory properties (McKenna et al., 2000; Arab and Il'yasova, 2003).

Recently, it was shown that epigallocatechin-3-gallate (EGCG), a major constituent of GTE, inhibits IL-1b-stimulation CC/CXC chemokine production, MMP-2 activation, IL-6 synthesis and trans-signalling in human RA synovial fibroblasts and rat adjuvant-induced arthritis (AIA) model (Ahmed at al., 2008).
Therefore, this study longitudinally analyzed levels of serum cartilage biomarkers and some proinflammtory cytokines during 24 weeks green tea therapy, taking the composition of aqueous green tea extract (AGTE) and its in vitro free radical scavenging activity into account to evaluate the feasibility of biomarkers for monitoring structural joint damage.

\section{PATIENTS AND METHODS}

\section{Controls}

In this study, a total of 80 patients were enrolled from the division of rheumatology and clinical immunology at Mansoura University, and all patients fulfilled the diagnostic criteria for RA according to American College of Rheumatology criteria (Arnett et al., 1988). Fifty patients with arthritis symptoms of $1.6 \pm 2.21$ duration were classified as having early RA, and 30 patients with disease duration of $4.17 \pm 2.21$ years were classified as showing established RA. Demographic and baseline characteristics of patients are shown in Table 1. All patients had clinically active disease, despite administration of conventional first-level disease-modifying antirheumatic drugs, and the mean 28-joint disease activity score (DAS28)-ESR at baseline was 5.4 for early RA and 6.6 for established RA. Only patients who were not receiving non-steroidal anti-inflammatory drugs and oral glucocorticoids (prednisoloneequivalents $\backslash 10 \mathrm{mg} /$ day) were included in the study. Furthermore, no intra-articular glucocorticoid injections were given during the study period or 3 months prior to enrolment. Patients are encouraged to follow a healthy, balanced diet that fosters a healthy weight. It is important to avoid elimination diets (Nutrition and Your Health, 1995). Dietary information was obtained from food diaries or by extensive dietary interviews. Patients were evaluated for therapeutic response at baseline and 12, and 24 weeks after starting green tea supplement (4 to 6 cups/day; 60 to $125 \mathrm{mg}$ catechins). In addition to comparison with the manufacturer's reference samples (below) and upper limit of normal, 50 healthy age matched blood donor volunteers acted as controls. The control subjects completed standard blood donor health questionnaires, but were not assessed clinically and did not have acute phase or immunogenetic studies. At each evaluation, blood samples were obtained and sera were separated and stored at $-80^{\circ} \mathrm{C}$ until needed for biomarker analysis. All laboratory investigations were performed in serum samples regarding informed consent obtained from RA patients. The study protocol was approved by ethical committee of Rheumatology and Clinical Immunology department, Mansoura University, Mansoura, Egypt.

\section{Analysis of phenolic compounds in AGTE}

Green tea, a commercial green tea drink produced by Kao Ltd. (Tokyo, Japan), was purchased from a convenience store. Total phenolic compounds of $100 \mathrm{mg}$ of GTE water extract were analyzed at Bio-technology Lab., Plant Pathology Institute, Agricultural Research Center, Giza, Egypt. Analysis was performed with a liquid chromatography "HP1050" equipped with a $4.6 \times 150$ $\mathrm{mm}$ ODS $\mathrm{C}_{18}$ column with UV detector and the injection volume was $5 \mu \mathrm{l}$. The mobile phase yielded results of $40 \%$ methanol:60\% distilled water. The wave length in the UV detector was $230 \mathrm{~nm}$, total run time for the separation was $15 \mathrm{~min}$ at a flow rate of 0.60 $\mathrm{ml} / \mathrm{min}$ according to the proposed method of Waskmundzka et al. (2007). Green tea has minimum contents of $540 \mathrm{mg}$ of catechins and $80 \mathrm{mg}$ of caffeine/350 $\mathrm{ml}$. 


\section{Studies of the in vitro antioxidant activity of AGTE}

The free radicals scavenging activity of green tea was determined using the 1,1-diphenyl-2-picryldrazil (DPPH) method (Ohinishi et al.,1994) and nitro blue tetrazolum (NBT) reduction method (Ravishankara et al., 2002) as the following.

\section{DPPH free radical scavenging assay}

One milliliter of DPPH solution $(0.1 \mathrm{mM}$ in ethanol) was mixed with $1 \mathrm{ml}$ of aqueous green tea extract (from 0 to $248 \mu \mathrm{g} / \mathrm{ml}$ ) and reacted for $30 \mathrm{~min}$. After that, absorbance of this mixture was measured at $517 \mathrm{~nm}$ against 95\% ethanol solution as the blank. Triplicate measurements were performed and the antioxidant activity was expressed as the percentage of scavenged DPPH:

Scavenging effect $(\%)=[(\mathrm{A} 0-\mathrm{A} 1) / \mathrm{A} 0] \times 100$

where $A 0$ and $A 1$ are the absorbance for the blank and green tea extract, respectively.

\section{NBT superoxide scavenging assay}

The reaction mixture contained: EDTA $(6 \mathrm{M})$, riboflavin $(2 \mu \mathrm{M})$, NBT $(50 \mu \mathrm{M})$, aqueous green tea extract (from 10 to $248 \mu \mathrm{g} / \mathrm{ml}$ ) and phosphate buffer $(67 \mathrm{mM}, \mathrm{pH} 7.8)$ in a final volume of $3 \mathrm{ml}$. The tubes were uniformly illuminated with an incandescent lamp for 15 min, and the optical density was measured at $530 \mathrm{~nm}$ before and after illumination.

\section{Clinical evaluation of therapeutic response}

The following clinical and laboratory parameters were longitudinally examined in each patient: CRP, Rf IgG antibodies, modified health assessment questionnaire (HAQ) score, pain numerical rating score (PNRS, 0 to 10) and DAS28-ESR. Scores for DAS28-ESR are reported using the erythrocyte sedimentation rate (Inoue et al., 2007) and were defined as follows: $\geq 4.1$, high activity; $\geq 2.7$ to $<4.1$, moderate activity; $\geq 2.3$ to $<2.7$, low activity; and $<2.3$, remission. DAS28ESR scores were assessed using EULAR response criteria. By comparing a patient's DAS28 score over multiple time points improvement or response of RA patients to green tea therapy was substantiated. The EULAR response criteria are defined as good $(>1.2)$, moderate $(0.6$ to 1.2$)$, and no response $(>0.6)$. In terms of radiographic analysis, radiographs of both hands and feet at baseline and 24 weeks were available for 43 patients in the early RA group and 26 patients in the established RA group. Two expert readers independently scored articular damage and progression in a blinded fashion according to the modified VDH-Sharp scoring method. Progression of TSS from baseline to week 24 (DTSS) was determined, and the proportion of patients with DTSS\#0 was calculated.

\section{Cartilage biomarkers analyses}

Serum samples obtained at baseline and after 12 and 24 weeks of green tea therapy were analysed for COMP by a sandwich ELISA utilizing two monoclonal antibodies directed against separate antigenic determinants on the human COMP molecule (AnaMar Medical, Lund, Sweden). The detection limit is $<0.1 \mu / L$ and the intra-assay and inter-assay coefficient of variation is $<5 \%$. Serum HA levels were determined using an HA Assay Kit (IBA method; Seikagaku, Tokyo, Japan) utilizing HA-binding protein.

\section{Statistical analyses}

Statistical analysis was carried out with Statistical Package for Social Science (SPSS) program version 10 for Windows (spss Inc, Chicago, IL, USA). Comparisons were done by Wilcoxon's matched-pairs test, the Mann-Whitney U-test, or the chi-square test where appropriate and correlations were calculated using Spearman's rank correlation coefficient. A $P$ value of $<0.05$ was considered significant.

\section{RESULTS}

Eighty patients with rheumatoid arthritis (RA) and 50 healthy control subjects were included in this study. Patients were classified according to the diagnostic criteria of rheumatology, DAS28-ESR, radiographic analysis, and RA biomarkers into two groups. Fifty patients with arthritis symptoms of $1.6 \pm 2.21$ duration and DAS28-ESR of 5.4 were classified as having early RA, and 30 patients with disease duration, $4.17 \pm 2.21$ years and DAS28-ESR of 6.6 were classified as showing established RA. The biochemical profile of rheumatoid and immunological markers along with $\mathrm{HA}$ and COMP cartilage biomarkers showed a significant $(P=0.01)$ correlation with the degree of RA as shown in Table 1.

The varieties of phenolic compounds in green tea extracts (AGTEs) were estimated using liquid chromategraphy. Catechins were the highest amount $(540 \mathrm{mg} / \mathrm{g})$ followed by caffeine $(80 \mathrm{mg} / \mathrm{g})$, chlorogenic acid $(22.47$ $\mathrm{mg} / \mathrm{g}$ ), and pyrogallol $(13.41 \mathrm{mg} / \mathrm{g})$. This was in addition to small amounts of other phenolic compounds such as vanillic, synergic, salycillic, benzoic and ferulic acids as shown in Table 2.

Also, the results of DPPH/NBT scavenging colorimetric assays confirm a high scavenging activity of AGTE, in which anti-radical activity is 90.3 and $87.9 \%$ at $64 \mu \mathrm{g} / \mathrm{ml}$ of AGTE against DPPH and NBT radicals, respectively. The potential decrease of the concentration of DPPH and NBT free radicals are due to AGTE scavenging activity as shown in Table 2.

As expected, laboratory indices for RA disease activity, such as CRP, ESR, Rf, DAS28-ESR, and body mass index (BMI) had decreased significantly by week 24 green tea supplement in both groups (Table 3). The decrease in DAS28-ESR was prominent in patients with early RA, with mean score at week 24 below the level of clinical remission as compared to baseline data. Also, mean PNRS score was significantly decreased at week 24 in the early and established RA groups as compared to baseline group. Similarly, a significant $(P=0.0001)$ decrease in BMI as demographic parameter was reported in both early and established RA groups during 24 week green tea supplement as compared to the data of baseline group (Table 3 ).

When DAS28-ESR scores were assessed using EULAR response criteria, 96 and $83 \%$ of patients were categorized as showing good or moderate response to 
Table 1. Demographics and baseline characteristics of the patients with early and established rheumatoid arthritis (RA) enrolled in this study.

\begin{tabular}{|c|c|c|c|}
\hline \multirow{2}{*}{ Parameter } & \multirow{2}{*}{ Control } & \multicolumn{2}{|c|}{ Rheumatoid arthritis (RA) } \\
\hline & & Early RA (<9 months) & Established RA (>10 years) \\
\hline No. of patients & 50 & 50 & 30 \\
\hline Gender (M/F) & $(30 / 20)$ & $(15 / 35)$ & $(12 / 18)$ \\
\hline Mean age (Year) & $45.4 \pm 4.7$ & $45.6 \pm 5.32^{*}$ & $55.6 \pm 12.41^{\star \star}$ \\
\hline BMI $\left(\mathrm{kg} / \mathrm{m}^{2}\right)$ & $23.2 \pm 3.2$ & $25.6 \pm 2.18^{*}$ & $26.9 \pm 3.20^{\star *}$ \\
\hline Duration of RA (years) & - & $8.6 \pm 2.21^{*}$ & $14.17 \pm 2.21^{\star *}$ \\
\hline$R F \lg G\left(U / m l^{2}\right)$ ELISA & $12.4 \pm 2.5$ & $92.8 \pm 28.5^{\star}$ & $110.8 \pm 31.4^{\star *}$ \\
\hline $\mathrm{ESR}(\mathrm{mm} / \mathrm{hr})$ & $16.9 \pm 7.5$ & $45.26 \pm 4.7^{*}$ & $56.4 \pm 5.2^{\star *}$ \\
\hline CRP (mg/L) & $1.85 \pm 0.72$ & $6.3 \pm 8.3^{*}$ & $8.5 \pm 5.6^{\star \star}$ \\
\hline COMP (ng/ml) ELISA & $21.6 \pm 4.6$ & $34.86 \pm 8.85^{*}$ & $45.9 \pm 11.2^{*}$ \\
\hline $\mathrm{HA}(\mathrm{ng} / \mathrm{ml})$ & $23 \pm 10.2$ & $42 \pm 9.23^{*}$ & $35 \pm 4.1^{*}$ \\
\hline TNF-œ (pg/ml) & $7.4 \pm 5.5$ & $35.35 \pm 12.56^{*}$ & $42.3 \pm 6.7^{\star *}$ \\
\hline IL-6 (pg/ml) & $10.4 \pm 2.3$ & $40.33 \pm 13.98^{*}$ & $56.36 \pm 17.6^{\star \star}$ \\
\hline DAS28-ESR & - & $5.4 \pm 0.43$ & $6.6 \pm 0.65^{\star *}$ \\
\hline Swollen joint counts & - & $9.8(0-28)$ & $11.6(0-28)$ \\
\hline Tender joint counts & - & 7.9 ( 0-28 & $8.5(0-28)$ \\
\hline HAQ score & - & $2.68(0.8-2.9)$ & $3.6(0.8-4.0)$ \\
\hline PNRS & - & $5.3 \pm 1.96$ & $6.2 \pm 2.85^{\star}$ \\
\hline
\end{tabular}

Except where indicated otherwise, values are expressed as the mean. ${ }^{*} \mathrm{P}<0.01$ versus baseline levels. ${ }^{*} \mathrm{P}<0.001$ versus baseline levels DAS28= Disease activity score-28; HAQ =Health Assessment Questionnaire score; PNRS= (Pain Numerical Rating Score;0-10); COMP = Cartilage Oligomeric Matrix Protein; CRP = C-reactive protein; ESR= erythrocyte sedimentation rate; TNF-œ = Tumor necrosis factor; Rf= Rheumatoid Factor; IL-6= interlukin-6.

Table 2. Phenolic compounds content $(\mathrm{mg} / \mathrm{g})$ and free-radical scavenging activities of $350 \mathrm{ml}$ aqueous green tea extract (AGTE) using liquid chromatography and spectrophotometry analysis.

\begin{tabular}{lc}
\hline Parameter & Phenolic content $(\mathbf{m g} / \mathbf{g})$ \\
\hline Phenolic component & 540 \\
Catechins (EGCG, ECG) & 80 \\
Caffeine & 22.47 \\
Chlorogenic acid & 13.41 \\
Pyrogallol & 4.69 \\
Vanillic & 1.94 \\
Synergic & 1.58 \\
Salycillic & 0.54 \\
POH benzoic & 0.53 \\
Ferulic & 0.11 \\
P-Coumatic acid & 0.09 \\
Coumarin & 0.1 \\
Naringinin & \\
AGTE scavenging activity & Free-radical scavenging activities at $\mathbf{6 4} \mathbf{\mu g} / \mathbf{m l}$ \\
\% Inhibition of DPPH reagent & $90.3 \%$ \\
\% Inhibition of NBT/Riboflavin reagent & $87.9 \%$ \\
\hline
\end{tabular}

green tea supplement in the early and established RA groups, respectively, with significant difference apparent between groups. Also, mean HAQ score was significantly decreased at week 24 in both the early and the established RA group (Table 3). Also, a significant decrease in inflammatory cytokines, such as TNF-œ and 
Table 3. Time-course changes in biochemical, clinical, radiographic, and functional measures during 24th week green tea therapy.

\begin{tabular}{|c|c|c|c|c|c|c|}
\hline \multirow{3}{*}{ Parameter } & \multicolumn{6}{|c|}{ Time after starting green tea supplement ( 4 to 6 cups/day) } \\
\hline & \multicolumn{2}{|c|}{$0 \mathrm{~W}$ (Baseline) } & \multicolumn{2}{|c|}{$12 \mathrm{~W}$} & \multicolumn{2}{|c|}{$24 \mathrm{~W}$} \\
\hline & Early RA & Established RA & Early RA & Established RA & Early RA & Established RA \\
\hline $\mathrm{BMI}\left(\mathrm{kg} / \mathrm{m}^{2}\right)$ & $25.6 \pm 1.8$ & $26.9 \pm 2.8$ & $24.9 \pm 1.4^{\star *}$ & $25.6 \pm 1.7^{\star *}$ & $23.8 \pm 1.2^{* *}$ & $24.5 \pm 1.9^{\star *}$ \\
\hline$R F \operatorname{lgG}\left(U / \mathrm{ml}^{2}\right)$ ELISA & $92.8 \pm 28.5$ & $110.8 \pm 31.4$ & $85.8 \pm 4.6^{\star *}$ & $98.8 \pm 17.4^{*}$ & $72.5 \pm 22.6^{\star *}$ & $85.3 \pm 18.3^{* *}$ \\
\hline $\mathrm{ESR}(\mathrm{mm})$ & $45.26 \pm 4.7$ & $56.4 \pm 5.2$ & $36.2 \pm 6.7^{\star *}$ & $48.6 \pm 5.2^{* *}$ & $25.8 \pm 2.5^{\star}$ & $32.2 \pm 2.8^{\star *}$ \\
\hline $\mathrm{CRP}(\mathrm{mg} / \mathrm{L})$ & $6.3 \pm 8.3$ & $8.5 \pm 5.6$ & $2.8 \pm 2.6^{* *}$ & $4.8 \pm 3.2^{* *}$ & $1.8 \pm 1.6^{*}$ & $2.7 \pm 2.3^{* *}$ \\
\hline DAS28-ESR & $5.4 \pm 0.43$ & $6.6 \pm 0.65$ & $4.3 \pm 0.16^{\star *}$ & $5.3 \pm 0.18^{\star *}$ & $2.4 \pm 1.6^{* *}$ & $2.6 \pm 2.13^{\star *}$ \\
\hline HAQ score & 2.38 & 3.2 & $1.96^{\star \star}$ & $2.9^{*}$ & $1.75^{\star \star}$ & $2.88^{*}$ \\
\hline TSS (SD) & $12.5(21.7)$ & $217.2(93.2)$ & n.d. & n.d. & $16.4(25.8)$ & $221.5(98.4)$ \\
\hline JNS (SD) & $5.7(8.6)$ & $87.5(46.3)$ & n.d. & n.d. & $9.6(12.7)$ & $91.3(48.3)$ \\
\hline DTSS (mean/median) & & & & & $4.2 / 0$ & $5.3 / 0$ \\
\hline Rate of DTSS\#0 [\%(cases)] & & & & & $72(31 / 43)$ & $77(20 / 26)$ \\
\hline PNRS & $5.3 \pm 1.96$ & $6.2 \pm 2.85$ & $3.36 \pm 0.73^{* *}$ & $4.9 \pm 0.53^{* *}$ & $2.32 \pm 0.83^{* *}$ & $3.8 \pm 0.61^{* *}$ \\
\hline \multicolumn{7}{|c|}{ EULAR category of response } \\
\hline Good (>1.2\%): & - & - & - & - & $40(50) ; 80 \%$ & $18(30) ; 60 \%$ \\
\hline Moderate (0.6 to $-1.2 \%)$ & - & - & - & - & $8(45) ; 16 \%$ & $7(30) ; 23 \%$ \\
\hline No response (> 0.6\%) & - & - & - & - & $2(45) ; 4 \%$ & $5(30) ; 17 \%$ \\
\hline
\end{tabular}

Except where indicated otherwise, values are expressed as the mean. ${ }^{*} \mathrm{P}<0.01$ versus baseline levels. ${ }^{* *} \mathrm{P}<0.001$ versus baseline levels; DAS28 $=$ Disease Activity Score-28; HAQ =Health Assessment Questionnaire score; PNRS= (Pain Numerical Rating Score;0-10); COMP=Cartilage Oligomeric Matrix Protein; CRP = C-reactive protein; ESR= erythrocyte sedimentation rate; TNF-œ = Tumor necrosis factor; Rf= Rheumatoid Factor; IL-6= interlukin-6;EULAR= European League against Rheumatism.

IL-6 were reported in both the early and established RA groups as compared to baseline data, suggesting that our clinical study using green tea yielded successful clinical results (Table 4).

Gradually, there were significant changes in serum levels of HA and COMP cartilage biomarkers during 24-week green tea therapy were reported in the early and established RA groups. The levels of $\mathrm{HA}$ and COMP cartilage biomarkers at weeks 12 and 24 were significantly lower than each base-line level $(P=0.001)$. The change in cartilage biomarkers appeared to synchronize with decreasing CRP, Rf, ESR levels along with DASESR and PNRS over the 24 weeks of green tea therapy (Table 4).

Radiographic structural assessment using the TSS revealed that mean DTSS per 6 month $(6$ month progression) was 4.2 in the early RA group and 5.3 in the established RA group, while the proportion with DTSS\#0 exceeded $70 \%$ in both groups, suggesting that our clinical study using green tea yielded successful clinical results (Table 3).

For both early and established RA groups, correlations between levels of cartilage biomarkers, biomarkers, inflammatory cytokines, and degree of RA disease activity (ESR, CRP, RF, and DAS28) were investigated according to EULAR category response at $24 \mathrm{~W}$ of green tea therapy. Several marker pairs with significant correlations are summarized in Table 5. A significant positive $(P=0.001)$ correlation for cartilage HA and COMP biomarkers towards the decrement of RA disease activity markers in good and moderate EULAR response grades was reported; however, negative significant $(P=0.01)$ correlation was reported in non-responder EULAR group which has no change in RA disease activity markers. Similarly, A 
Table 4. Time-course changes in the levels of cartilage and inflammatory biomarkers during 24th week green tea therapy.

\begin{tabular}{lcccccc}
\hline \multirow{2}{*}{ Parameter } & \multicolumn{4}{c}{ Time after starting Green Tea supplement (4-6 cups/day) } \\
\cline { 2 - 7 } & \multicolumn{2}{c}{ OW (Baseline) } & \multicolumn{2}{c}{ 12W } & \multicolumn{2}{c}{ 24 W } \\
& Early RA & Established RA & Early RA & Established RA & Early RA & Established RA \\
\hline COMP $(\mathrm{ng} / \mathrm{ml})$ ELISA & $34.86 \pm 8.85$ & $45.9 \pm 11.2$ & $28.15 \pm 2.6^{* *}$ & $32.15 \pm 3.4^{* *}$ & $18.5 \pm 3.22^{\star *}$ & $23.5 \pm 2.7^{* *}$ \\
HA $(\mathrm{ng} / \mathrm{ml})$ & $42 \pm 9.23$ & $35 \pm 4.1$ & $38.5 \pm 6.23$ & $29.4 \pm 4.2$ & $28.5 \pm 3.5$ & $22.3 \pm 2.7$ \\
TNF-œ $(\mathrm{pg} / \mathrm{ml})$ & $35.35 \pm 12.56$ & $42.3 \pm 6.7$ & $26.2 \pm 3.2^{*}$ & $27.15 \pm 1.7^{*}$ & $20.4 \pm 3.65^{*}$ & $16.2 \pm 2.4^{* *}$ \\
IL-6 $(\mathrm{pg} / \mathrm{ml})$ & $40.33 \pm 13.98$ & $56.36 \pm 17.6$ & $24.3 \pm 2.5^{* *}$ & $30.27 \pm 3.5^{\star *}$ & $20.21 \pm 4.0^{* *}$ & $26.4 \pm 2.0^{* *}$ \\
\hline
\end{tabular}

Except where indicated otherwise, values are expressed as the mean. ${ }^{*} \mathrm{P}<0.01$ versus baseline levels. ${ }^{* *} \mathrm{P}<0.001$ versus baseline levels; COMP $=$ cartilage oligomeric matrix protein; TNF-œ = tumor necrosis factor; IL-6= interlukin-6.

significant positive $(P=0.01)$ correlation for inflammatory cytokines TNF-œ and IL-6 towards the decrement of RA disease activity markers in good and moderate EULAR response grades was reported; however, negative significant $(P=0.01)$ correlation was reported in non-responder EULAR group which has no change in RA disease activity markers (Table 5).

\section{DISCUSSION}

Rheumatoid arthritis (RA) is a chronic inflammatory disease characterized by the activation of synovial tissue lining the joint capsule, which results in severe morbidity and subsequent physical disability (Pope, 2002).

The traditional treatments for arthritis improve the inflammatory component of the disease and lead to reduced pain and swelling. However, it lacks activity against degenerative process of cartilage (Dingle, 1991). Therefore, the identification of common dietary substances of natural plant origin capable of affording beneficial protection or modulating the onset and severity of arthritis may have important health implications (Berman, 2004).
Green tea (Camellia sinensis) has been extensively evaluated by its potential anti-rheumatic activity due to its higher content of polyphenols known as catechins (30 to $36 \%$ of dry weight) including epigallocatechin-3-gallate (EGCG), which constitutes up to $63 \%$ of total catechins (Manning and Roberts, 2003).

In this study before studying the anti-rheumatic activity of green tea, the polyphenol content and free radical scavenging activity of aqueous green tea leave extracts (AGTE) were estimated using liquid chromatography and DPPH/NBT scavenging colorimetric assays.

Analysis of AGTE showed higher content of polyphenols. Catichins amount were the highest between all phenolic compounds, where it represented $32.6 \mathrm{mg} / \mathrm{g}$ followed by caffeine $(25.84$ $\mathrm{mg} / \mathrm{g})$, chlorogenic acid $(22.47 \mathrm{mg} / \mathrm{g})$ and pyrogallol $(13.41 \mathrm{mg} / \mathrm{g})$. This is in addition to small amounts of other phenolic compounds such as vanillic, synergic, salycillic, benzoic and ferulic. Similar levels were shown by Hoff and Singleton (1997). However, different results of total polyphenol content ( 80.5 to $134.9 \mathrm{mg} / \mathrm{g}$ and 65.8 to $106.2 \mathrm{mg} / \mathrm{g}$ ) in black and green tea leaves were obtained by Khokhar and Magnusdottir (2002), this may be related to brewing time, commercial brand, and producing country.

Also, this study shows higher activity of AGTE, in which anti-radical activity was about 90.3 and $87.9 \%$ at $64 \mu \mathrm{g} / \mathrm{ml}$ of AGTE against DPPH and NBT radicals, respectively. The potential decrease in the concentration of DPPH and NBT radicals are due to the scavenging ability of AGTE. These results were in accordance with other studies (Yen and Chen, 1997; Yokozawa et al., 1998), which reported higher radicals scavenging efficiency of green tea extract. Also, green tea polyphenols were widely reported as significant antioxidant, anti-carcinogenic, anti-inflammatory, thermogenic, probiotic, and antimicrobial properties (Graham, 1992; Alschuler, 1998).

To study anti-rheumatic activity of green tea, 80 patients with early and established rheumatoid arthritis were subjected to 12, 24 week green tea supplement (4 to 6 cups/day), whereas a cup of green tea typically provides 60 to $125 \mathrm{mg}$ catechins, including EGCG (Cooper et al., 2005).

In this study, patients with early and established RA showed an increase in BMI which correlates significantly with disease activity and pro-inflammatory state of RA patients. The association of BMI with disease activity could be due to physical inactivity leading to an increase in BMI (Dessein et 
Table 5. Spearman's correlation coefficients of cartilage and inflammatory biomarkers versus RA disease markers (ESR, Rf, CRP, and DAS28-ESR) according to EULAR category of response at 24 week of green tea therapy.

\begin{tabular}{|c|c|c|c|c|c|c|}
\hline \multirow{3}{*}{ Item } & \multicolumn{6}{|c|}{ EULAR category response at $24 \mathrm{~W}$ of green tea therapy } \\
\hline & \multicolumn{3}{|c|}{ Early RA (Spearman's r) } & \multicolumn{3}{|c|}{ Established RA (Spearman's r) } \\
\hline & $\begin{array}{l}\text { Good } \\
(n=40)\end{array}$ & $\begin{array}{c}\text { Moderate } \\
(\mathrm{n}=8)\end{array}$ & $\begin{array}{c}\text { No Response } \\
(n=2)\end{array}$ & $\begin{array}{c}\text { Good } \\
(n=18)\end{array}$ & $\begin{array}{c}\text { Moderate } \\
(n=7)\end{array}$ & $\begin{array}{c}\text { No Response }(\mathrm{n}= \\
5)\end{array}$ \\
\hline \multicolumn{7}{|c|}{ Cartilage biomarker } \\
\hline COMP vs ESR & $0.32^{\star \star}$ & $0.21 * *$ & $-0.35^{\star}$ & $0.5^{\star \star}$ & $0.63^{* *}$ & $-0.51^{*}$ \\
\hline vs Rf & $0.12^{* *}$ & $0.41^{* *}$ & $-0.65^{\star}$ & $0.25^{\star \star}$ & $0.73^{* *}$ & $-0.31^{*}$ \\
\hline vs CRP & $0.42^{* \star}$ & $0.81^{* *}$ & $-0.55^{\star}$ & $0.45^{\star *}$ & $0.83^{* *}$ & $-0.91^{*}$ \\
\hline vs DAS28 & $0.49^{\star \star}$ & $0.78^{* *}$ & $-0.95^{\star}$ & $0.48^{\star *}$ & $0.33^{* *}$ & $-0.53^{*}$ \\
\hline HA vs ESR & $0.24^{* *}$ & $0.35^{\star *}$ & $-0.42^{*}$ & $0.34^{\star *}$ & $0.71^{* *}$ & $-0.34^{*}$ \\
\hline vs $R f$ & $0.64^{* *}$ & $0.55^{\star *}$ & $-0.62^{*}$ & $0.44^{\star *}$ & $0.51^{* *}$ & $-0.37^{*}$ \\
\hline vs CRP & $0.56^{\star \star}$ & $0.25^{\star \star}$ & $-0.48^{*}$ & $0.53^{\star \star}$ & $0.68^{* *}$ & $-0.41^{*}$ \\
\hline vs DAS28 & $0.49^{* *}$ & $0.75^{\star *}$ & $-0.32^{*}$ & $0.64^{\star *}$ & $0.70^{* *}$ & $-0.35^{*}$ \\
\hline \multicolumn{7}{|l|}{$\begin{array}{l}\text { Inflammatory } \\
\text { biomarker }\end{array}$} \\
\hline TNF-œ vs ESR & $0.37^{\star}$ & $0.91^{*}$ & $-0.25^{\star *}$ & $0.35^{*}$ & $0.75^{*}$ & $-0.59^{\star *}$ \\
\hline vs Rf & $0.29^{*}$ & $0.85^{*}$ & $-0.27^{\star *}$ & $0.45^{\star}$ & $0.80^{*}$ & $-0.61^{\star *}$ \\
\hline vs CRP & $0.43^{*}$ & $0.75^{\star}$ & $-0.23^{* *}$ & $0.55^{\star}$ & $0.82^{*}$ & $-0.70^{* *}$ \\
\hline vs DAS28 & $0.47^{*}$ & $0.68^{*}$ & $-0.31^{* *}$ & $0.25^{*}$ & $0.67^{*}$ & $-0.73^{* *}$ \\
\hline IL-6 vs ESR & $0.45^{\star}$ & $0.81^{*}$ & $-0.43^{\star *}$ & $0.58^{*}$ & $0.25^{*}$ & $-0.68^{* *}$ \\
\hline vs Rf & $0.49^{*}$ & $0.87^{*}$ & $-0.38^{* *}$ & $0.52^{*}$ & $0.35^{*}$ & $-0.71^{* *}$ \\
\hline vs CRP & $0.65^{\star}$ & $0.79^{*}$ & $-0.36^{* *}$ & $0.56^{*}$ & $0.31^{*}$ & $-0.75^{\star *}$ \\
\hline vs DAS28 & $0.58^{*}$ & $0.72^{*}$ & $-0.40^{* *}$ & $0.61^{*}$ & $0.30^{*}$ & $-0.78^{\star *}$ \\
\hline
\end{tabular}

Values are correlation coefficients calculated using Spearman's rank correlation. $\mathrm{P}$ values are expressed in parentheses. $\mathrm{P}<0.05$ is considered as statistically significant. ${ }^{*} \mathrm{P}<0.01$ and ${ }^{* *} \mathrm{P}<0.001$.

(Dessein et al., 2007; Sokka et al., 2008). Therefore, BMI may consider as a predictor of RA disease activity.

When patients with early and established RA treated with green tea therapy for 12 and 24 weeks, BMI was greatly reduced towards normal values compared to baseline data. The control of higher BMI towards normal values may be related to green tea's thermogenic effect properties as a result of a synergistic interaction between caffeine and catechin polyphenols that appears to prolong sympathetic stimulation of thermogenesis (Dulloo et al., 2000; Juhel et al., 2000). This matched with Maki et al. (2009) who reported that, the consumption of 625 mg EGCG-containing catechins daily for 24 weeks caused a greater loss of body weight and a decrease in the fasting serum triglyceride levels in the catechinadministered group. Also data showed that the decrease in BMI was significantly correlated with reduction in the parameters of RA disease activity DAS28 and PNRS during 24 week green tea therapy indicating the antirheumatic activity of green tea and the importance of BMI as a predictor of RA disease activity (Sokka et al., 2008).

In the present study, patients with early and established RA treated with green tea therapy for 24 week showed a significant decrease in clinical measures of disease activity such as CRP, Rf and ESR as compared to baseline data. The decrease in disease activity measures exhibited significant correlation with enhancement of DAS28-ESR and PNRS criteria. The established pharmacological properties of green tea are attributed to its high content of EGCG (Doss et al., 2005; Cooper et al., 2005). The antirheumatic activity of green tea supplement may be related to certain pathways such as the modulation of energy balance, endocrine system, food intake, lipid and carbohydrate metabolism, antiobesity, anti-inflammatory, and redox status (Yang et al., 2001; Sabu et al., 2010).

Recent understanding of the RA pathogenesis has clarified the role of cytokines and other inflammatory mediators in this process and has provided a scientific rationale in developing targeted therapies (Feldmann and Maini, 2008), whereas cytokines such as IL-1B, TNF-œ, and IL-6 promote imbalance between excessive cartilage destruction and cartilage repair processes via induction of reactive oxygen species (ROS) and inflammatory mediators (Malemud, 2004).

Our results showed elevated levels of TNF- $\alpha$ and IL-6 in early and established RA groups which coincided with previous studies (Dube et al., 2008; Patrick et al., 2010). These results were reversed by supplementation of green 
tea therapy for 24 week. The reported beneficial effects of green tea may be related to their antioxidant, antiinflammatory and antiproteinase properties of its phenolic contents (Frei and Higdon, 2003), the anti-inflammatory effects of green tea may partially be due to its ability to regulate TNF- $\alpha$ gene expression, encoding antiinflammatory/pro-inflammatory factors (Wahyudi and Sargowo, 2007). The decrease in the level of TNF- $\alpha$ and IL-6 was supported with a significant correlation between disease activity parameters and the improvement of DAS28-ESR and PNRS criteria, whereas the level of cytokines and RA disease parameters especially CRP are interrelated (Hye Soon Parka et al., 2005; Patrick et al., 2010). The obtained results may be related to the ROs-scavenging activity of green tea catechins (Chen et al., 2004; Erba et al., 2005; Riegsecker et al., 2013).

Soon after a discovery that GT polyphenols may inhibit arthritis in murine model, majority of the studies were focused on its beneficial effect on progressive cartilage degradation, a hallmark of OA and RA (Malemud, 2006).

In this study, a significant increase in both serum HA and COMP levels was reported at baseline stage of patients with early and established RA. However, patients with established RA showed a higher HA and COMP values as compared to early group. This may be related to the severity of joint damage due to physical activity (Mundermann et al., 2005). The elevation of serum COMP and HA showed a significant correlation with the parameters of RA disease activity, especially DAS28ESR and PNRS. The correlation of these parameters in patients demonstrating low values of traditional prognostic markers including ESR, CRP, RF and DAS was greatly reported (Månsson et al., 1999; Skoumal et al., 2004). Additionally, COMP may be of prognostic value for radiological outcome and proposed its feasibility in monitoring articular cartilage damage in RA (Skoumal et al., 2003; Young-Min et al., 2007; Morozzi et al., 2007).

Also, in the present study, there was a significant decrease in the level of COMP and HA in both groups with RA during the initial 6 months of green tea therapy. This suggests that green tea modifies the release of COMP and HA from the tissue and supports the interpretation that this treatment modality retards the development of joint destruction. Interestingly, some recent pharmacological studies using EGCG or green tea to suppress arthritis have focused equally on bone resorption observed in RA (Lin et al., 2009; Natsume et al., 2009; Takai et al., 2008).

The EULAR response criteria classify patients as good, moderate or non-responders, using the individual amount of change in the DAS28 according to patients responding for novel treatments or clinical trials (Smolen et al., 2003; Fransen et al., 2003).

In the present study, the response of RA patients to green tea treatment at 24 week was reported using DAS28-ESR and EULAR response criteria. When
DAS28-ESR scores were assessed using EULAR response criteria, 96 and $83 \%$ of patients were categorized as showing good or moderate response in the early and established RA groups, respectively with no significant difference apparent between groups. However, 4 and $17 \%$ of patients were non-responders at 24 week green tea therapy. The data obtained showed a significant correlation between the decrease in the levels of CRP, ESR, Rf, IL- 6 and TNF- $\alpha$ in good and moderate green tea RA responders as compared to nonresponders, whereas the disease activity remained unchanged. These results demonstrated the antirheumatic activity of green tea which may be related to the antioxidant and anti-inflammatory of its phenolic compounds, especially catechins (Morinobu et al., 2008; Lin et al., 2008). Also, many studies reported that treatment of green tea reduced oxidative stress free radicals induced production of proinflammatory cytokines TNF- $\alpha, \quad$ IL-6, CRP and NF-kB activation in a dose dependent manner (Kim et al, 2000; Wahyudi and Sargowo, 2007; Ramesh et al., 2009).

Similarly, in the present study radiographic structural assessment using the TSS revealed that mean DTSS per 6 month (6 month progression) was 4.2 in the early RA group and 5.3 in the established RA group, while the proportion with DTSS\#0 exceeded $70 \%$ in both groups, suggesting that our clinical study using green tea yielded successful clinical results comparable to those in a previous study in Japan (Takeuchi et al., 2008), which reported the notable efficacy of infliximab therapy in a rheumatoid arthritis management.

Finally, according to EULAR response criteria, elevated serum levels of $\mathrm{HA}$ and COMP were significantly decreased in all groups of good, moderate and nonresponders to green tea therapy at 24 week. Our results showed that green tea treatment inhibited the degradation of human cartilage through enhancement of the serum levels of HA and COMP cartilage biomarkers as previously reported (Adcocks et al., 2002; Vankemmelbeke et al., 2003; Ahmed et al., 2004; Niki et al., 2012). Also, it could be hypothesized that the effect might be due to the joint protective effect suggested for green tea polyphenols (Lambert et al., 2007). Our results further confirm the conclusion that COMP levels are highly specific markers for the cartilage degradation process in RA (Di Cesare et al., 1999), and could be used as biomarker for clinical treatments.

\section{Conclusion}

The pattern of changes of serum cartilage biomarkers (HA and COMP) and inflammatory cytokines (IL-6, TNF$œ)$ in patients with early and established RA, supports the interpretation that green tea has a joint protective and anti-inflammatory effect. Serum cartilage biomarkers could 
be useful for evaluating tissue effects of novel treatment modalities in rheumatoid arthritis. Our results suggest that this promising anti-arthritic activity of green tea should be further explored as a dietary therapy for the management of $R A$ in conjunction with conventionally used drugs.

\section{ACKNOWLEDGEMENT}

The authors extend their appreciation to the Deanship of Scientific Research at King Saud University for funding the work through the research group project NO. RGPVPP-209.

\section{ABBREVIATIONS}

RA, Rheumatoid arthritis; ECM, extracellular matrix; DAS28, disease activity score-28; PNRS, pain numerical rating score 0-10; COMP, cartilage oligomeric matrix protein; CRP, C-reactive protein; ESR, erythrocyte sedimentation rate; TNF-œ, tumor necrosis factor; Rf, rheumatoid factor; IL-6, interlukin-6; AGTE, aqueous green tea extract; EGCG, epigallocatechin-3-gallate; DPPH, 1,1-diphenyl-2-picryldrazil; NBT, nitro blue tetrazolum; EULAR, European league against rheumatism response criteria.

\section{Authors' contributions}

All the authors contributed equally to this study, read and approved final version of manuscript.

\section{Conflict of Interest}

The authors declare that they have no competing interests.

\section{REFERENCES}

Adcocks C, Collin P, Buttle DJ (2002). Catechins from green tea (Camellia sinensis) inhibit bovine and human cartilage proteoglycan and type II collagen degradation in vitro. J. Nutr. 132:341-346.

Ahmed S, Marotte H, Kwan K, Ruth JH, Campbell PL, Rabquer BJ, Pakozdi A, Koch AE (2008). Epigallocatechin-3-gallate inhibits IL-6 synthesis and suppresses trans signaling by enhancing soluble gp130 production. Proc. Natl. Acad. Sci. USA105:14692-7.

Ahmed S, Rahman A, Hasnain A, Lalonde M, Goldberg VM, Haqqi TM (2002). Green tea polyphenol epigallocatechin-3-gallate inhibits the IL-1 $\beta$-induced activity and expression of cyclooxygenase-2 and nitric oxide synthase-2 in human chondrocytes. Free Radic. Biol. Med. 33:1097-1105.

Ahmed S, Wang N, Lalonde M, Goldberg VM, Haqqi TM (2004). Green tea polyphenol epigallocatechin-3-gallate (EGCG) differentially inhibits interleukin-1 beta-induced expression of matrix metalloproteinase-1 and-13 in human chondrocytes. J. Pharmacol.
Exp. Ther. 308:767-773.

Alschuler L (1998). Green Tea: Healing tonic. Am. J. Nat. Med. 5:2831.

Arab L, Il'yasova D (2003). The epidemiology of tea consumption and colorectal cancer incidence. J. Nutr. 133:S3310-8.

Arnett FC, Edworthy SM, Bloch DA, McShane DJ, Fries JF, Cooper NS, Healey LA, Kaplan SR, Liang MH, Luthra HS, Medsger TA Jr., Mitchell DM, Neustadt DH, Pinals RS, Schaller JG, Sharp JT, Wilder RL, Hunder GG (1988). The American Rheumatism Association 1987 revised criteria for the classification of rheumatoid arthritis. Arthritis Rheum. 31:315-324.

Berman B (2004). Complementary and alternative medicine: is it just a case of more tools for the medical bag? Clin. J. Pain 20:1-2.

Brosseau L, Wells GA, Tugwell P, Egan M, Wilson KG, Dubouloz CJ, Casimiro L, Robinson VA, McGowan J, Busch A, Poitras S, Moldofsky H, Harth M, Finestone HM, Nielson W, Haines-Wangda A, Russell-Doreleyers M, Lambert K, Marshall AD, Veilleux L; Ottawa Panel Members (2004). Ottawa panel evidence-based clinical practice guidelines for therapeutic exercises in the management of rheumatoid arthritis in adults. Phys. Ther. 84(10):934-972.

Chen JH, Tipoe GL, Liong EC, So HS, Leung KM, Tom WM, Fung PC, Nanji AA (2004). Green tea polyphenols prevent toxin-induced hepatotoxicity in mice by down-regulating inducible nitric oxidederived prooxidants. Am. J. Clin. Nutr. 80:742-751.

Choy EH, Panayi GS (2001). Cytokine pathways and joint infl ammation in rheumatoid arthritis. N. Engl. J. Med. 344: 907-16.

Cooper R, Morre DJ, Morre DM (2005). Medicinal benefits of green tea: part I. Review of non-cancer health benefits. J. Altern. Compl. Med. 11:521-528.

den Broeder AA, Joosten L, Saxne $T$, Heinegard $D$, Fenner $H$, Miltenburg A, Frasa W, van Tits LJ, Buurman W, van Riel PLCM, van de Putte LBA, Barrera P (2002). Long term anti-tumour necrosis factor alpha monotherapy in rheumatoid arthritis: effect on radiological course and prognostic value of markers of cartilage turnover and endothelial activation. Ann Rheum Dis.61:311-8.

Dessein PH, Norton GR, Woodiwiss AJ, Joffe BI, Solomon A (2007). Independent role of conventional cardiovascular risk factors as predictors of $\mathrm{C}$-reactive protein concentrations in rheumatoid arthritis. J. Rheumatol. 34:681-8.

Di Cesare PE, Fang C, Leslie MP, Della Valle CJ, Gold JM, Tulli H, Perris R, Carlson CS (1999). Localization and expression of cartilage oligomeric matrix protein by human rheumatoid and osteoarthritic synovium and cartilage. J. Orthop. Res. 17:437-445.

Dingle JT (1991). Cartilage maintenance in osteoarthritis: interaction of cytokines, NSAID and prostaglandins in articular cartilage damage and repair. J. Rheumatol. 18: 30-37.

Doss MX, Potta SP, Hescheler J, Sachinidis A (2005). Trapping of growth factors by catechins: a possible therapeutical target for prevention of proliferative diseases. J. Nutr. Biochem. 16:259-266.

Dube B, Rita T B, Satya P, Kalra A, Michael G (2008). Increased leptin expression selectively in the hypothalamus suppresses inflammatory markers CRP and IL-6 in leptin-deficient diabetic obese mice. Peptides 29: 593-598.

Dulloo AG, Seydoux J, Girardier L, Chantre P, Vandermander J (2000). Green tea and thermogenesis: interactions between catechin polyphenols, caffeine, and sympathetic activity. Int. J. Obes. Relat. Metab. Disord. 24:252-258.

Ekdahl C, Broman G (1992). Muscle strength, endurance, and aerobic capacity in rheumatoid arthritis: a comparative study with healthy subjects. Ann. Rheum. Dis. 51(1):35-40.

Erba D, Riso P, Bordoni A, Foti P, Biagi PL, Testolin G (2005). Effectiveness of moderate green tea consumption on antioxidative status and plasma lipid profile in humans. J. Nutr. Biochem. 16:144 9.

Feldmann M, Maini SR (2008). Role of cytokines in rheumatoid arthritis: an education in pathophysiology and therapeutics. Immunol. Rev. 223:7-19.

Firesten GS (2004). The T cell cometh: Interplay between adaptive immunity and cytokine networks in rheumatoid arthritis. J. Clin. Invest. 114: 471-4. 
Fransen J, Stucki G, Van Rielplc M (2003). Rheumatoid arthritis measures. Arthritis Rheum. 49 (Suppl.5):S214-24.

Frei B, Higdon JV (2003). Antioxidant activity of tea polyphenols in vivo: evidence from animal studies. J. Nutr. 133:3275S-84S.

Graham HN (1992). Green tea composition, consumption, and polyphenol chemistry. Prev. Med. 21:334-350.

Haqqi TM, Anthony DD, Gupta S, Ahmad N, Lee MS, Kumar GK, Mukhtar H (1999). Prevention of collagen-induced arthritis in mice by a polyphenolic fraction from green tea. Proc. Natl. Acad. Sci. USA 96:4524-4529.

Hitchon CA, Alex P, Erdile LB, Frank MB, Dozmorov I, Tang Y, Wong K, Centola M, El-Gabalawy HS (2004). A distinct multi-cytokine profi le is associated with anti-cyclical citrullinated peptide antibodies in patients with early untreated inflammatory arthritis. J. Rheumatol. 31:2336-46

Hoff JF, Singlengleton KIA (1997). A method for determination of tannin in foods by means of immobilized enzymes. J. Food Sci. 42:1566.

Hye SP, Jung YP, Rina Y (2005). Relationship of obesity and visceral adiposity with serum concentrations of CRP, TNF- $\alpha$ and IL-6. Diabetes Res. Clin. Pract. 69:29-35.

Inoue E, Yamanaka H, Hara M, Tomatsu T, Kamatani N (2007). Comparison of Disease Activity Score (DAS)-28- erythrocyte sedimentation rate and DAS28- C-reactive protein threshold values. Ann. Rheum. Dis. 66:407-409.

Juhel C, Armand M, Pafumi Y, Rosier C, Vandermander J, Lairon D (2000). Green tea extract (AR25) inhibits lipolysis of triglycerides in gastric and duodenal medium in vitro. J. Nutr. Biochem. 11:45-51.

Khokhar S, Magnusdottir SGM (2002). Total phenol, catechin and caffeine contents of teas commonly consumed in the United Kingdom. J. Agric. Food Chem. 50:565.

Kim S, Lee MJ, Hong J, Li C, Smith TJ, Yang GY, Seril DN, Yang CS (2000). Plasma and tissue levels of tea catechins in rats and mice during chronic consumption of green tea polyphenols. Nutr. Cancer 37:41-48.

Kremers HM, Nicola P, Crowson CS, Michael O' fallon W, Gabriel SE (2004). Therapeutic strategies in rheumatoid arthritis over a 40-year period. J. Rheumatol. 31:2366-2373.

Kroot EJ1, de Jong BA, van Leeuwen MA, Swinkels $H$, van den Hoogen $\mathrm{FH}$, van't Hof M, van de Putte LB, van Rijswijk MH, van Venrooij WJ, van Riel PL (2000). The prognostic value of anti-cyclic citrullinated peptide antibody in patients with recent-onset rheumatoid arthritis. Arthritis Rheum. 43:1831-1835.

Lambert JD, Sang S, Yang CS (2007). Biotransformation of green tea polyphenols and the biological activities of those metabolites. Mol. Pharm. 4:819-25.

Lin RW, Chen $\mathrm{CH}$, Wang $\mathrm{YH}$, Ho ML, Hung SH, Chen IS, Wang GJ (2009). (-)-Epigallocatechin gallate inhibition of osteoclastic diff erentiation via NF-kB. Biochem. Biophys. Res. Commun. 379:10331037.

Lin SK, Chang HH, Chen YJ, Wang CC, Galson DL, Hong CY, Kok SH (2008). Epigallocatechin-3-gallate diminishes CCL2 expression in human osteoblastic cells via up-regulation of phosphatidylinositol 3Kinase/Akt/ Raf-1 interaction: a potential therapeutic benefit for arthritis. Arthritis Rheum. 58:3145-3156.

Lipsky PE (2005). Rheumatoid arthritis. In: Kasper D, Braunwald E, Fauci A, Hauser S, Longo D, Jameson J (eds.), Harrison's principles of internal medicine, 16th ed. New York: McGraw-Hill.

Majeed M, McQueen F, Yeoman S, McLean L (2004).Relationship between serum hyaluronic acid level and disease activity in early rheumatoid arthritis. Ann. Rheum. Dis. 63:1166-1168 doi:10.1136/ard.2003.010942

Maki KC, Reeves MS, Farmer M, Yasunaga K, Matsuo N, Katsuragi Y, Komikado M, Tokimitsu I, Wilder D, Jones F, Blumberg JB, Cartwright $Y$ (2009). Green tea catechin consumption enhances exercise-induced abdominal fat loss in overweight and obese adults. J. Nutr. 139:264-270.

Malemud CJ (2004). Cytokines as therapeutic targets for osteoarthritis. Biol. Drugs 18:23-35.

Malemud CJ (2006). Matrix metalloproteinases: role in skeletal development and growth plate disorders. Front. Biosci. 11:1702-15.
Manning J, Roberts JC (2003). Analysis of catechin content of commercial green tea products. J. Herbal Pharmacother. 3:19-32.

Månsson $\mathrm{B}$, Carey $\mathrm{D}$, Alini $\mathrm{M}$, lonescu $\mathrm{M}$, Rosenberg LC, Poole $\mathrm{AR}$, Heinegård D, Saxne T (1995).Cartilage and bone metabolism in rheumatoid arthritis. Differences between rapid and slow progression of disease identified by serum markers of cartilage metabolism. $\mathrm{J}$ Clin. Invest. 95:1071-7.

McInnes IB (2001). Rheumatoid arthritis: From bench to bedside Rheum. Dis. Clinics North Am. 27(2):373-387.

McKenna DJ, Hughes K, Jones K (2000). Green tea monograph. Altern. Ther. Health Med. 6:61-8, 70-2, 4.

Morinobu A, Biao W, Tanaka S, Horiuchi M, Jun L, Tsuji G, Sakai Y, Kurosaka M, Kumagai S (2008). (-)-Epigallocatechin-3-gallate suppresses osteoclast differentiation and ameliorates experimental arthritis in mice. Arthritis Rheum. 58:2012-2018.

Morozzi G, Fabbroni M, Bellisai F, Cucini S, Simpatico A, Galeazzi M (2007). Low serum level of COMP, a cartilage turnover marker, predicts rapid and high ACR70 response to adalimumab therapy in rheumatoid arthritis. Clin. Rheumatol. 26:1335-1338.

Mundermann A, Dyrby CO, Andriacchi TP, King KB (2005). Serum concentration of cartilage oligomeric matrix protein (COMP) is sensitive to physiological cyclic loading in healthy adults. Osteoarthritis Cartilage 13:34-38.

Natsume $\mathrm{H}$, Adachi $\mathrm{S}$, Takai $\mathrm{S}$, Tokuda $\mathrm{H}$, Matsushima-Nishiwaki $\mathrm{R}$, Minamitani C, Yamauchi J, Kato K, Mizutani J, Kozawa O, Otsuka T (2009). (-)-Epigallocatechin gallate attenuates the induction of HSP27 stimulated by sphingosine 1-phosphate via suppression of phosphatidylinositol 3-kinase/Akt pathway in osteoblasts. Int. J. Mol. Med. 24:197-203.

Niki Y, Takeuchi T, Nakayama M, Nagasawa H, Kurasawa T, Yamada $\mathrm{H}$, Toyama Y, Miyamoto T (2012). Clinical Significance of Cartilage Biomarkers for Monitoring Structural Joint Damage in Rheumatoid Arthritis Patients Treated with Anti-TNF Therapy. PLoS ONE 7(5): $\mathrm{e} 37447$.

Nutrition and Your Health: Dietary Guidelines for Americans (1995). U.S. Department of Agriculture, U.S. Department of Health and Human Services. 4th edition.

Ohinishi M, Morishita H, Iwahashi H, Shizuo T, Yoshiaki S, Kimura M, Kido R (1994). Inhibitory effects of chologenic acids on linoleic acid peroxidation and haemolysis. Phytochemistry 36:579-583.

Patrick B, Tobias B, Rüdiger H, Georg B, Roland J, Felix B, Michael S, Heike N (2010). Dietinduced obesity, exogenous leptin-, and MADB106 tumor cell challenge affect tissue leukocyte distribution and serum levels of cytokines in F344 rats. Endocrinology 38:104112.

Pope RM (2002). Apoptosis as a therapeutic tool in rheumatoid arthritis. Nat. Rev. Immunol. 2:527-535.

Ramesh E, Geraldine P, Thomas PA (2009). Regulatory effect of epigallocatchin gallate on the expression of $\mathrm{C}$-reactive protein and other inflammatory markers in an experimental model of atherosclerosis. Chem. Biol. Interact. [Epub ahead of print].

Ravishankara M N, Shrivastava N, Padh H, Rajani M (2002). Evaluation of antioxidant properties of root bark of Hemidesmus indicus $\mathrm{R}$. $\mathrm{Br}$. (Anantmul). Phytomedicine 9:153-160.

Riegsecker S, Wiczynski D, Kaplan MJ, Ahmed S (2013). Potential benefits of green tea polyphenol EGCG in the prevention and treatment of vascular inflammation in rheumatoid arthritis. Life Sci. 3;93(8):307-12

Sabu MC, Priya TT, Ramadsan K, Ikuo Nishigaki1 I (2010). Beneficial effect of green tea; A literature review. Chin. Med 5:13.

Sattar N, McCarey DW, Capell H, Mclnnes IB (2003). Explaining how "high-grade "systemic inflammation accelerates vascular risk in rheumatoid arthritis. Circulation 108(24):2957-2963.

Saxne T, Månsson B (2000). Molecular markers for assessment of cartilage damage in rheumatoid arthritis. In: Firestein G, Panayi GS Wollheim FA (eds.), Rheumatoid Arthritis: New Frontiers in Pathogenesis and Treatment. Oxford: Oxford University Press. pp. 291-304.

Singh R, Ahmed S, Islam N, Victor M. Goldberg VM, Haqqi TM (2002). Epigallocatechin-3- gallate inhibits interleukin-1 $\beta$-induced expression 
of nitric oxide synthase and production of nitric oxide in human chondrocytes: suppression of nuclear factor $\mathrm{KB}$ activation by degradation of the inhibitor of nuclear factor $\mathrm{kB}$. Arthritis Rheum. 46:2079-2086.

Skoumal M, Haberhauer G, Feyertag J, Kittl EM, Bauer K, Dunky A (2004). Serum levels of cartilage oligomeric matrix protein are elevated in rheumatoid arthritis, but not in inflammatory rheumatic diseases such as psoriatic arthritis, reactive arthritis, Raynaud's syndrome, scleroderma, systemic lupus erythematosus, vasculitis and Sjögren's syndrome. Arthritis Res. Ther. 6:73-74.

Skoumal M, Kolarz G, Klingler A (2003). Serum levels of cartilage oligomeric matrix protein. A predicting factor and a valuable parameter for disease management in rheumatoid arthritis. Scand. J. Rheumatol. 32:156-61.

Smith JB, Haynes MK (2002). Rheumatoid arthritis; a molecular understanding. Ann. Intern. Med. 136:908-22.

Smolen JS, Breedveld FC, Schiff MH, Kalden JR, Emery P, Eberl, G, van Riel PL, Tugwell P (2003). A simplified disease activity index for rheumatoid arthritis for use in clinical practice. Rheumatology 42:244-57.

Sokka T, Häkkinen A, Kautiainen H, Maillefert JF, Toloza S, Mørk Hansen T, Calvo-Alen J, Oding R, Liveborn M, Huisman M, Alten R, Pohl C, Cutolo M, Immonen K, Woolf A, Murphy E, Sheehy C, Quirke E, Celik S, Yazici Y, Tlustochowicz W, Kapolka D, Skakic V, Rojkovich B, Müller R, Stropuviene S, Andersone D, Drosos AA, Lazovskis J, Pincus T; QUEST-RA Group (2008). Physical inactivity in patients with rheumatoid arthritis: data from twenty-one countries in a cross-sectional, international study. Arthritis Rheum. 59:42-50.

Takai S, Matsushima-N R, Adachi S, Natsume IH, Minamitani C, Mizutani J, Otsuka T, Tokuda H, Kozawa O (2008). (-)Epigallocatechin gallate reduces platelet-derived growth factor-BBstimulated interleukin-6 synthesis in osteoblasts: suppression of SAPK/JNK. Mediators Inflamm. 2008: 291808.
Takeuchi T, Yamanaka H, Inoue E, Nagasawa H, Nawata M, Ikari K, Saito K, Sekiguchi N, Sato E, Kameda H, Iwata S, Mochizuki T, Amano K, Tanaka Y (2008). Retrospective clinical study on the notable efficacy and related factors of infliximab therapy in a rheumatoid arthritis management group in Japan: one year outcome of joint destruction (RECONFIRM-2J). Mod Rheumatol. 18:447-454.

Vankemmelbeke MN, Jones GC, Fowles C, Ilic MZ, Handley CJ, Day AJ, Knight CG, Mort JS, Buttle DJ (2003). Selective inhibition of ADAMTS $-1,-4$ and -5 by catechin gallate esters. Eur. J. Biochem. 270:2394-2403.

Wahyudi S, Sargowo D (2007). Green tea polyphenols inhibits oxidized LDL- induced NKKB activation in human umbilical vein endothelial cell. Acta Med. Indones. 39(2): 66-70.

Waskmundzka M, Wianowska D, Szewczyk K, Oniszczuk A (2007). Effect of sample-preparation methods on the HPLC quantitation of some phenolic acids in plant materials. Acta Chromatographica 19:227-237.

Yang $\mathrm{MH}$, Wang $\mathrm{CH}$, Chen $\mathrm{HL}$ (2001). Green tea, Oolong and black tea extract modulate lipid metabolism in hyper lipidemic rats fed high sucrose diet. J. Nutr. Biochem. 12:14-20.

Yen GC, Chen HY (1997). Antioxidant activity of various tea extracts in relation to their mutagenicity. J. Agric. Food Chem. 43:27.

Yokozawa T, Dong E, Nakagawa T, Kashiwagi $H$, Nakagawa $H$, Takeuchi S, Chung HY (1998). In vitro and in vivo studies on the radical-scavenging activity of tea. J. Agric. Food Chem. 46:2143.

Young-Min S, Cawston T, Marshall N, CoadyD, Christgau S, Saxne T, Robins S, Griffiths I (2007). Biomarkers predict radiographic progression in early rheumatoid arthritis and perform well compared with traditional markers. Arthritis Rheum. 56:3236-3247. 